\title{
An Overview on Omnichannel Inventory Strategy under Uncertain Demand
}

\author{
Qian Du \\ School of Management, Jinan University, Guangzhou, China \\ Email: duqianvera@163.com
}

How to cite this paper: Du, Q. (2021). An Overview on Omnichannel Inventory Strategy under Uncertain Demand. American Journal of Industrial and Business Management, 11, 525-535.

https://doi.org/10.4236/ajibm.2021.115033

Received: April 27, 2021

Accepted: May 22, 2021

Published: May 25, 2021

Copyright $\odot 2021$ by author(s) and Scientific Research Publishing Inc. This work is licensed under the Creative Commons Attribution International License (CC BY 4.0).

http://creativecommons.org/licenses/by/4.0/

\begin{abstract}
With the improvement of people's living standards, there are higher requirements for product quality and personalization. At the same time, the development of science and technology, such as big data, cloud computing, VR, etc., provides technical support to meet the higher shopping needs of consumers. Promoted by these two factors, omnichannel came into being. In the omnichannel model, a single demand may exist in multiple channels, which increases the difficulty of retailer demand forecasting and brings challenges to the inventory management of omnichannel retailers. This article sorts out and analyzes the changes in omnichannel consumer demand, the relationship between channels, and the related research on multi-channel and omnichannel inventory strategies, and finds that there are few studies on omnichannel inventory strategies. At present, the research on omnichannel inventory strategy is mostly based on a specific omnichannel model inventory strategy research. The characteristics of omnichannel such as changes in demand and channel relationship have not been included in the relevant research. The characteristics of omnichannel such as changes in demand and channel relationship have not been included in the relevant research. This paper proposes that future research can pay more attention to the impact of the new characteristics of the omnichannel model on inventory management, as well as the challenges of inventory management caused by the competition and cooperation between channels, and provide a scientific basis for omnichannel inventory management.
\end{abstract}

\section{Keywords}

Uncertain Demand, Omnichannel, Inventory Strategy

\section{Introduction}

Since the rapid development of e-commerce in 2011, online retail has begun to 
develop rapidly and impact physical retail with its efficient consumer experience (from the consumer side, online shopping saves customers time and transportation costs). From 2014 to 2016, the scale of online e-commerce retail transactions gradually expanded. Until 2017, traditional e-commerce users increased due to the widespread use of the Internet and mobile Internet terminals and the traffic dividends were gradually shrinking. According to a report from Xueqiu.com in October 2019, the average customer acquisition cost of Tmall and JD.com has doubled six times in five years, from 150 yuan in 2014 to 964.5 yuan in 2018 . Pure online channels cannot bring more advantages to enterprises, and the "bottleneck" of online growth is beginning to appear.

Since online channels and offline channels are different in their ability to provide product information (Coughlan et al., 2006), online consumers have some uncertainty about product attributes, so they cannot be sure whether the product really meets their needs (Chu and Zhang, 2011; Prasad et al., 2011). This uncertainty will reduce consumers' willingness to pay (Grewal et al., 1994; Teo and Yeong, 2003), increase the possibility of online consumers returning goods, and increase the retailer's operating costs. Therefore, for consumers who are very familiar with e-commerce, purchasing products online can reduce the transportation cost and time cost of shopping, but because they cannot experience the product, they cannot accurately determine whether the product meets their needs and preferences. Therefore, consumers often choose to return products when they buy unsatisfactory products. The 2020 China Live E-commerce Industry Research Report pointed out that the current average return rate of traditional e-commerce industry is $10 \%-15 \%$, and the average return rate of live e-commerce is as high as $30 \%-50 \%$. Based on the above market conditions, retailers have begun to integrate online and offline channels in order to provide consumers with a better shopping experience.

Omnichannel retailers generally have two or more channels. While integrating these channels, retailers also face complex inventory management issues. The survey results of omnichannel retailers show that more than $80 \%$ of retailers believe that making reasonable inventory decisions is one of the biggest challenges for omnichannel operations (Gallino et al., 2017). In an omnichannel environment, consumers are showing trends such as channel shifts, multi-line purchases, and personalized demand (Chen et al., 2019), which increases the difficulty for retailers to predict demand. Take Hema as an example. In the case of Hema overtime, a single SKU may present demand in the form of multiple channels. Hema Xiansheng must determine the inventory in the warehouse and storefront before uncertain demand appears in several consecutive time frames (each 30 minutes). Demand uncertainty is an important factor affecting the inventory holding level and inventory efficiency of retailers (Kull et al, 2013), and a reasonable inventory strategy is an important strategy for retailers to reduce the impact of demand uncertainty on inventory.

Omnichannel integration of online and offline channels, and its inventory management involves the coordination and optimization of multiple stakeholders. 
This article first sorts out the development history and definition of omnichannel, and on this basis, sorts out and analyzes the changes in consumer demand of omnichannel, the relationship between channels, and relevant research on multi-channel and omnichannel inventory strategies, and finally prospects The future development trend of new retail.

\section{Definition and Development History of Omnichannel}

\subsection{Definition of Omnichannel}

Rigby (2011) puts forward that omnichannel means that companies adopt as many types of retail channels as possible to combine and integrate sales to ensure seamless connection between different channels. In the omnichannel model, consumers will use a variety of channels to interact with retailers before purchasing goods. For example, consumers may go to the physical store to observe and experience the product before purchasing the product online. Different from traditional single-channel retail operations, there are multiple contact points between consumers and retailers in an omnichannel environment, and companies provide multiple ways to meet consumer needs at the same time. Li (2013) believes that omnichannel means that companies adopt as many retail channel types as possible to combine and integrate (cross-channel) sales behaviors to meet customers' comprehensive experience needs of shopping, entertainment and social interaction. Under the omnichannel retail model, consumers can purchase the goods and services they want at anytime, anywhere, and anyway. It integrates physical channels, e-commerce channels, and mobile commerce. Channels and more emerging channels to provide customers with an undifferentiated buying experience. Based on the definition of omnichannel by the above scholars, this article believes that omnichannel refers to the linking of two or more online and offline channels, and integrates the advantages of online services and offline experience, and brings consumers high-quality shopping Experience.

\subsection{Development History of Omnichannel}

In 2011, Rigby first put forward the concept of omnichannel in Harvard Business Review. At the same time, Macy's in the United States and Uniqlo in Japan have all begun to implement the omnichannel strategy of "order online, store pickup (BOPS)", an omnichannel model Officially landed abroad. In October 2016, Jack Ma first proposed the concept of "new retail" at the Hangzhou Yunqi Conference. He believes that "the era of pure e-commerce will soon end. In the future, offline and online retail will be deeply integrated, coupled with modern logistics, and service providers will use big data, cloud computing and other innovative technologies to form the concept of new retail in the future." In October 2017, the General Office of the State Council issued the "Guiding Opinions on Actively Promoting Supply Chain Innovation and Application", emphasizing the establishment of standards and competition rules that adapt to integrated development, guiding physical retail enterprises to gradually improve their in- 
formatization level, and integrating offline logistics and services. Integrate advantages such as, experience, and online business flow, capital flow, and information flow to expand the intelligent and networked layout. Since then, omnichannel new retail has developed rapidly in China. The domestic omnichannel layout began with the development of offline channels by online retailers and the development of online channels by offline retailers. In 2017, Alibaba and Yintai Commercial jointly developed new retail models such as smart home stores and unmanned clothing stores for Yintai. JD.com began to deploy its offline channels, JD Home, JD Stores, and JD Maternal and Child Experience Stores. Xiao$\mathrm{mi}$, an online mobile phone retailer, opened its first offline flagship experience store, realizing price and online connections. In July 2019, the three squirrels were successfully listed, and 560 million of the raised investment funds were used for omnichannel construction. With the gradual development of the omnichannel model, fresh food retailers such as Hema Xiansheng, Yonghui Supermarket, 7-fresh, etc., have established and opened up online and offline channels at the same time. The omnichannel model has become a development trend in the retail industry.

\section{Omnichannel Strategy}

The emergence of the omnichannel retail model is to solve the problem of consumers' uncertainty about products, on the other hand, it can also improve the efficiency of online order fulfillment.

From the perspective of solving consumer product uncertainty, retailers have adopted methods such as establishing physical exhibition halls, virtual exhibition halls, and disclosing inventory information to provide convenience for consumers to understand product information. If a retailer has established a physical showroom, then consumers can now learn about product information in the physical showroom, and then place an order online. We call this method "showrooming". When products can be sold in physical exhibition halls, consumers can also learn about products online, and then experience and purchase products offline. This phenomenon is called "webrooming". Through these two methods, the consumer can eliminate his uncertainty about the product. The virtual exhibition hall relies on VR technology to display products to consumers. Although it cannot completely eliminate consumers' uncertainty about the product, it can provide consumers with more product information compared to pure online e-commerce. Understand the product. Customers of Christian Dior can experience the Dior beauty store in Paris Champs Elysees online through 360degree virtual reality. This virtual reality allows them to view the products on the shelves with just a click of a mouse, just like in a physical store.

In order to improve the efficiency of online order fulfillment, retailers provide different order fulfillment methods. The most common omnichannel order fulfillment method is "order online, pick up offline (BOPS)", there are also "order online, ship to store (BOSS)", "order online, in-store delivery (BOFS)" and "on- 
line purchase, physical store return (BORP)" and so on. At present, relevant research mainly focuses on the "BOPS" model (Gallino \& Moreno, 2014; Gao and Su, 2017).

\section{Omnichannel Strategy and Consumer Demand Change}

Retailers with multiple channels can segment consumers according to channels (Konus et al., 2008; De Keyser et al., 2015). For example, retailers with online and offline channels can divide consumers into online consumers and online consumers. For consumers, the corresponding demand can also be divided into online demand and offline demand. Gao and Su (2017) studied the impact of online and offline self-service ordering technologies (interaction of online and offline channels) on customer demand and company profits. Gallino and Moreno (2014) empirically studied the impact of BOPS on retailer online and offline channel sales, and found that the implementation of BOPS will lead to a decrease in online sales and an increase in physical store sales and traffic. Further research by Hübner et al. (2016) found that the reason for the BOPS model to reduce online sales, increase offline sales and increase the rate of customer visits is: additional store sales brought by the purchase of other products in the store when consumers using BOPS go to the store to pick up the goods, and some BOPS consumers shifted from online to offline physical stores and from noncustomers to BOPS consumers, which led to the increase in offline shop visits and sales. Gallino et al. (2017) analyzed data from US retailers using the "order online, delivery to store" (BOSS) model, and found that BOSS will increase the sales gap between various products in physical stores. Bell et al. (2018) studied the impact of the introduction of showrooms on online retailers. Their empirical results show that the showroom not only increased online sales and overall sales, but also improved operational efficiency. Jing (2018) researched that the addition of online channels by traditional retailers will expand the demand of traditional retailers. From the above research results, retailers can increase the total demand or the demand of a single channel (online or offline) by adopting the omnichannel model. At the same time, there is also the phenomenon of consumer channel shift, which may lead to competition between channels, and then Influencing retailers' inventory decisions.

\section{Competition and Synergy between Channels}

Inventory control strategies depend on the relationship between online channels and physical stores (Saha and Bhattacharya, 2020). The channel development of the retail industry has gone through a single-channel, dual-channel, multi-channel process to the current omnichannel process. The omnichannel emphasizes the integration of online service efficiency and offline experience to provide consumers with the best consumer experience. Omnichannel can be seen as the further development of dual-channel or multi-channel, and there are still the characteristics of dual-channel and multi-channel. According to previous research 
results, dual-channel retailers with online e-commerce platforms and offline physical stores are facing serious channel competition problems. Webb \& Hogan (2002) have found that retailers opening online channels will cause conflicts between retailers' dual channels due to competition for market demand. When the sales products between channels are similar, the conflicts between channels will be aggravated, which will inevitably reduce the overall efficiency of the channels. Yan and Pei's (2009) research shows that the opening of online channels by retailers will cause consumers in offline channels to shift to online channels to purchase products, causing conflicts between online and offline channels due to competition for more market demand. There is price competition between online and offline channels. Cattani et al. pointed out that the important reason for the conflict between online and offline channels is the product pricing problem of different channels (Cattani et al., 2006). Online channels can provide consumers with lower prices and attract more consumers by directly ordering from manufacturers, attracting traffic, and selling lower-quality products, which will further aggravate the contradiction between online and offline channels.

Similarly, even in the omnichannel model, there are similar channels and market demand competition issues. Gao and Su (2017) found that retailers' adoption of the BOPS model would cause consumers to move to offline stores, leading to higher store operating costs. Since offline stores and online channels are managed separately, it is recommended to share BOPS revenue between channels to reduce channels Conflict. However, some studies have found that omnichannel retail has a synergistic effect. The different channels of omnichannel retailers are not simply competing with each other, but there are mutual promotion and enhancement effects (Mcgoldrick and Collins, 2007).

Different from dual-channel and multi-channel, omnichannel channels not only have a competitive relationship but also a cooperative relationship, and there is less research on the omnichannel competition and cooperation relationship. Channel relationship affects the changes in demand in different channels and changes in total demand. It is very important to specify a reasonable inventory strategy in retail. It is necessary to increase the research on the competition and cooperation relationship between omnichannels.

\section{Omnichannel Inventory Strategy}

Schwartz (1966) believes that consumers' lack of stock will affect consumers' willingness to buy again and inhibit consumer demand (1966), but excess inventory will also lead to increased inventory costs for retailers. How to specify an appropriate inventory strategy in an omnichannel model with multi-channel demand has become one of the most critical issues facing omnichannel retailers.

\subsection{Horizontal Inventory Sharing Strategy}

Horizontal inventory sharing strategy is one of the important strategies to solve the problem of multi-channel inventory management. Inventory sharing occurs 
before and after the warehouse is out of stock, and flexible inventory allocation is used to meet the needs of consumers. Horizontal inventory sharing refers to purchasing goods from the same level retailer or warehouse when a warehouse is out of stock. Sharing can be carried out periodically at predetermined points in time to actively redistribute inventory, or they can be used reactively as a method to meet demand that cannot be met by existing inventory (Paterson et al., 2011). For continuous-time, single-level, multi-location inventory systems with Poisson demand processes, retailers use horizontal transshipment to share inventory to solve the shortage problem. Each warehouse is assigned a predetermined sequence of other warehouses, and horizontal transshipment is requested in this sequence. However, the warehouse can keep the last part of such a request. This is called a retention pool strategy, in which each warehouse has a retention level, which is used to determine whether another warehouse's request for horizontal transfer sharing is satisfied. The study by Van et al. (2012) demonstrated the benefits of retention levels and explained how to set retention levels through heuristic algorithms. Based on the cost/service effect of inventory sharing in service parts logistics, Iyoob \& Kutanoglu (2013) studied which facilities should store inventory sharing pools. Compared with more systematic transshipment techniques based on inventory level equalization, temporary emergency transshipment methods seem to be more effective in terms of several important criteria (Burton \& Banerjee, 2005). Lee et al. (2007) proposed a new horizontal transshipment policy called Service Level Adjustment (SLA). SLA combines emergency lateral transshipment with preventive lateral transshipment to effectively respond to customer needs. Liang et al. (2014) found that when there are many retail stores, the additional benefits of two-way transshipment are negligible. Retailers have online channels, and online demand is met by the physical stores closest to consumers in this omnichannel model, there is a unique inventory order level Nash equilibrium and optimal transshipment prices, so that the entire supply chain To maximize profits (Zhao et al., 2016).

\subsection{Effective Inventory Management of Multi-Channel Supply}

Omnichannel involves two or more channels, so channel supply is also one of the key points in inventory management. Xue et al. (2017) studied how to adjust the inventory of products in display racks and warehouses according to product attributes and designed the optimal inventory strategy. Acimovic and Graves (2015) studied the optimal replenishment allocation to fulfillment centers to reduce transportation costs and mitigate costly spillover effects. DeValve et al. (2018) studied the benefits of increasing execution flexibility for inventory stores of large online retailers by combining allocation strategies based on random programs and execution strategies that limit satiable overflow demand. Wollenburg et al. (2016) found that inventory management (cross-channel inventory information, product delivery speed, etc.) can guide consumers in channel selection. 


\subsection{Inventory Strategy for Omnichannel Model}

Hübner et al. (2016) investigated retail fulfillment in an integrated omnichannel environment, and suggested that retailers operating through multiple channels should design their warehouse systems for channel-integrated inventory management. When omnichannel retailers with physical stores and online fulfillment center networks face demand from both online and offline, when online and in-store demands are moderately mixed, the price of choosing a centralized inventory plan is the best for retailers (Govindarajan et al., 2018). Hu et al. (2021) studied the three models of "order online, pick up offline (BOPS)", "order online, delivery to store (BOSS)" and "order online, store delivery (BOFS)" for retailers online and offline. The impact of channel inventory sharing. They found that delivery time and physical store distribution density are important factors that affect retailers' inventory costs and inventory availability after inventory optimization. BOSS saves the last mile delivery cost and eliminates the separation of requirements in BOPS. Chen et al. (2018) aimed at the Hema Fresh Food omnichannel model, before uncertain demand appears in several consecutive time frames (each 30 minutes), inventory coordination between the warehouse and the storefront. The problem of using robust optimization was modeled and solved.

The problem of omnichannel inventory decision-making in a dynamic environment. Acimovic \& Graves (2015) developed a demand-satisfaction heuristic algorithm for online retailers with multiple locations and multiple modes of transportation. Saha and Bhattacharya (2020) found that inventory control strategies will also depend on the relationship between online channels and physical stores. If both are under the same ownership, then the store will set the best basic inventory level to serve walk-in orders and BOPS orders with the same priority; when the ownership of the two channels is different, there must be a revenue between the two Sharing arrangements, and based on the percentage of revenue received from each BOPS order, the store can decide to prioritize the incoming order. Bayram and Cesaret (2020) took the transportation cost of each location as an independent random variable, and considered the best dynamic fulfillment decision of the omnichannel retail network when giving the initial inventory level.

The current inventory strategy research mainly focuses on the research on inventory sharing and transshipment in multiple channels, while the research on all-channel inventory is less. In the future, relevant inventory research can be carried out based on the needs of omnichannels and the characteristics of the channels.

\section{Conclusion}

With the improvement of people's living standards, the increase in personalized demand, and the rapid development of technologies such as big data and VR, omnichannel has become an important business model that retailers need to consider. At present, many retailers in the industry have implemented omni- 
channel practices, and they are facing many problems in the process of integrating online and offline channels. This article sorts out the omnichannel development process, the relationship between omnichannel implementation and changes in consumer demand, the relationship between channels, and based on the above current omnichannel demand and channel relationship combing, sorting out some current multi-channel and omnichannel inventory strategies Aspects of research. At present, there are few researches on inventory strategy for omnichannel and most of them are about inventory research under BOPS mode. Based on the current research status of omnichannel inventory management, this article believes that future research can focus more on the impact of the new characteristics of the omnichannel model on inventory management, as well as the challenges of inventory management caused by the competition and cooperation between channels, etc., for omnichannel inventory Management provides scientific basis.

This article only focuses on the competition and cooperation between channels, inventory management issues under the omnichannel environment, and inventory strategies under different omnichannel strategies, but for the big data, machine learning, and machine learning that drive retailers to choose the omnichannel model. The impact of artificial intelligence and other technologies on the channel competition and cooperation relationship network and the related issues of its operation mechanism have not been researched. The research on omnichannel management is still in its infancy. Inventory management is only one aspect of omnichannel management. Collaboration between channels, the applications of new technologies, and return management are all problems faced by omnichannel companies. "Study, study and research" promotes the resolution of omnichannel management problems in many aspects.

\section{Conflicts of Interest}

The author declares no conflicts of interest regarding the publication of this paper.

\section{References}

Acimovic, J., \& Graves, S. C. (2015). Making Better Fulfillment Decisions on the Fly in an Online Retail Environment. Manufacturing \& Service Operations Management, 17, 34-51. https://doi.org/10.1287/msom.2014.0505

Bayram, A., \& Cesaret, B. (2020). Order Fulfillment Policies for Ship-from-Store Implementation in Omnichannel Retailing. European Journal of Operational Research. https://doi.org/10.1016/j.ejor.2020.01.011

Bell, D. R., Gallino, S., \& Moreno, A. (2018). Offline Showrooms in Omnichannel Retail: Demand and Operational Benefits. Management Science, 64, 1629-1651. https://doi.org/10.1287/mnsc.2016.2684

Burton, J., \& Banerjee, A. (2005). Cost-Parametric Analysis of Lateral Transshipment Policies in Two-Echelon Supply Chains. International Journal of Production Economics, 93-94, 169-178.

Cattani, K., Gilland, W., Heese, H. S., \& Swaminathan, J. (2006). Boiling Frogs: Pricing Strategies for a Manufacturer Adding a Direct Channel That Competes with the Tradi- 
tional Channel. Production and Operations Management, 15, 40-56. https://doi.org/10.1111/j.1937-5956.2006.tb00002.x

Chen, L., Jin, R., Qin, H., Simchi-Levi, D., \& Zhang, Z. (2019). Distributionally Robust Omnichannel Stocking Decisions in Quick Fulfillment Systems. https://doi.org/10.2139/ssrn.3383881

Chen, X. Y., Wo, C. H., \& Yu, Y. P. (2018). New Consumer Power-2018 China Consumer Insights Series Report.

https://www.accenture.com/cn-zh/insight-consumers-in-the-new

Chu, L. Y., \& Zhang, H. (2011). Optimal Preorder Strategy with Endogenous Information Control. Management Science, 57, 1055-1077. https://doi.org/10.1287/mnsc.1110.1335

Coughlan, A., Anderson, E., Stern, L. W., Lansary, A. E., \& Hall, P. (2006). Marketing Channels: United States Edition. Zug: Pearson Schweiz AG.

De Keyser, A., Schepers, J., \& Konuş, U. (2015). Multichannel Customer Segmentation: Does the After-Sales Channel Matter? A Replication and Extension. International Journal of Research in Marketing, 32, 453-456. https://doi.org/10.1016/j.ijresmar.2015.09.005

DeValve, L., Wei, Y., Wu, D., \& Yuan, R. (2018). Understanding the Value of Fulfillment Flexibility in an Online Retailing Environment. https://doi.org/10.2139/ssrn.3265838

Gallino, S., \& Moreno, A. (2014). Integration of Online and Offline Channels in Retail: The Impact of Sharing Reliable Inventory Availability Information. Management Science, 60, 1434-1451. https://doi.org/10.1287/mnsc.2014.1951

Gallino, S., Moreno, A., \& Stamatopoulos, I. (2017). Channel Integration, Sales Dispersion, and Inventory Management. Management Science, 63, 2813-2831.

https://doi.org/10.1287/mnsc.2016.2479

Gao, F., \& Su, X. (2017). Omnichannel Retail Operations with Buy-Online-and-PickUp-in-Store. Management Science, 63, 2478-2492. https://doi.org/10.1287/mnsc.2016.2473

Govindarajan, A., Sinha, A., \& Uichanco, J. (2018). Joint Inventory and Fulfillment Decisions for Omnichannel Retail Networks. Naval Research Logistics.

Grewal, D., Gotlieb, J., \& Marmorstein, H. (1994). The Moderating Effects of Message Framing and Source Credibility on the Price-Perceived Risk Relationship. Journal of Consumer Research, 21, 145-153. https://doi.org/10.1086/209388

Hu, M., Xu, X., Xue, W., \& Yang, Y. (2021). Demand Pooling in Omnichannel Operations. Management Science. https://doi.org/10.1287/mnsc.2021.3964

Hübner, A. H., Kuhn, H., Wollenburg, J., Towers, N., \& Kotzab, H. (2016). Last Mile Fulfillment and Distribution in Omnichannel Grocery Retailing: A Strategic Planning Framework. International Journal of Retail \& Distribution Management, 44, 228-247. https://doi.org/10.1108/IJRDM-11-2014-0154

Iyoob, I. M., \& Kutanoglu, E. (2013). Inventory Sharing in Integrated Network Design and Inventory Optimization with Low-Demand Parts. European Journal of Operational Research, 224, 497-506. https://doi.org/10.1016/j.ejor.2012.09.033

Jing, B. (2018). Showrooming and Webrooming: Information Externalities between Online and Offline Sellers. Marketing Science, 37, 469-483.

https://doi.org/10.1287/mksc.2018.1084

Konus, U., Verhoef, P. C., \& Neslin, S. A. (2008). Multichannel Shopper Segments and Their Covariates. Journal of Retailing, 84, 398-413. https://doi.org/10.1016/j.jretai.2008.09.002

Kull, T. J., Barratt, M., Sodero, A. C., \& Rabinovich, E. (2013). Investigating the Effects of Daily Inventory Record Inaccuracy in Multichannel Retailing. Journal of Business Lo- 
gistics, 34, 189-208. https://doi.org/10.1111/jbl.12019

Lee, Y. H., Jung, J. W., \& Jeon, Y. S. (2007). An Effective Lateral Transshipment Policy to Improve Service Level in the Supply Chain. International Journal of Production Economics, 106, 115-126. https://doi.org/10.1016/j.ijpe.2006.05.007

Li, F. (2013). The Meaning, Causes and Countermeasures of Omnichannel Retailing-Revisiting to Meet the Revolutionary Storm of Multi-Channel Retailing. Journal of Beijing Technology and Business University: Social Science Edition, 2, 1-11.

Liang, C., Sethi, S. P., Shi, R., \& Zhang, J. (2014). Inventory Sharing with Transshipment: Impacts of Demand Distribution Shapes and Setup Costs. Production and Operations Management, 23, 1779-1794. https://doi.org/10.1111/poms.12197

McGoldrick, P. J., \& Collins, N. (2007). Multichannel Retailing: Profiling the Multichannel Shopper. International Review of Retail, Distribution and Consumer Research, 17, 139-158. https://doi.org/10.1080/09593960701189937

Paterson, C., Kiesmüller, G., Teunter, R., \& Glazebrook, K. (2011). Inventory Models with Lateral Transshipments: A Review. European Journal of Operational Research, 210, 125136. https://doi.org/10.1016/j.ejor.2010.05.048

Prasad, A., Stecke, K. E., \& Zhao, X. (2011). Advance Selling by a Newsvendor Retailer. Production and Operations Management, 20, 129-142. https://doi.org/10.1111/j.1937-5956.2010.01133.x

Rigby, D. (2011). The Future of Shopping. Harvard Business Review, 89, 65-76.

Saha, K., \& Bhattacharya, S. (2020). "Buy Online and Pick Up In-Store”: Implications for the Store Inventory. European Journal of Operational Research. https://doi.org/10.1016/j.ejor.2020.10.006

Schwartz, B. L. (1966). A New Approach to Stockout Penalties. Management Science, 12, B538-B544. https://doi.org/10.1287/mnsc.12.12.B538

Teo, T. S., \& Yeong, Y. D. (2003). Assessing the Consumer Decision Process in the Digital Marketplace. Omega, 31, 349-363. https://doi.org/10.1016/S0305-0483(03)00055-0

Van Wijk, A. C. C., Adan, I. J., \& van Houtum, G. J. (2012). Approximate Evaluation of Multi-Location Inventory Models with Lateral Transshipments and Hold Back Levels. European Journal of Operational Research, 218, 624-635. https://doi.org/10.1016/j.ejor.2011.12.004

Webb, K. L., \& Hogan, J. E. (2002). Hybrid Channel Conflict: Causes and Effects on Channel Performance. Journal of Business \& Industrial Marketing, 17, 338-356. https://doi.org/10.1108/08858620210439031

Wollenburg, J., Mena, C., Bourlakis, M., Hübner, A., \& Holzapfel, A. (2016). Retail Logistics in the Transition from Multi-Channel to Omnichannel. International Journal of Physical Distribution \& Logistics Management, 46, 562-583.

Xue, W., Caliskan Demirag, O., Chen, F. Y., \& Yang, Y. (2017). Managing Retail Shelf and Backroom Inventories when Demand Depends on the Shelf-Stock Level. Production and Operations Management, 26, 1685-1704. https://doi.org/10.1111/poms.12713

Yan, R., \& Pei, Z. (2009). Retail Services and Firm Profit in a Dual-Channel Market. Journal of Retailing and Consumer Services, 16, 306-314. https://doi.org/10.1016/j.jretconser.2009.02.006

Zhao, F., Wu, D., Liang, L., \& Dolgui, A. (2016). Lateral Inventory Transshipment Problem in Online-to-Offline Supply Chain. International Journal of Production Research, 54, 1951-1963. https://doi.org/10.1080/00207543.2015.1070971 